\title{
Self-trust, trust/distrust to other people in volunteers
}

\begin{abstract}
The article considers the level of self-trust as a system forming factor of the prosocial activity of volunteers. It is shown that volunteers with a high level of self-trust are characterized by less psychological distance in the relationship of trust to others, which is based on identity, while volunteers with an average level of self-trust relate to others on knowledge. Volunteers with a low level of self-trust in prosocial behavior in the course of interaction replace their trust with other interchange taking into account their own interests.
\end{abstract}

Keywords: self-trust, trust and distrust to other people, criteria of trust, altruism, egoism, social responsibility, volunteering, prosocial activity
Volume 9 Issue 6 - 2018

\author{
Aldasheva Aigul Abdulhaevna,' Loginova \\ Mariya Aleksandrovna,' Runets Oksana \\ Vladimirovna ${ }^{2}$ \\ 'Department of Psychology, State Academic University for \\ Humanities, Russia \\ ${ }^{2}$ Laboratory of Work and Organizational Psychology, Institute of \\ Psychology, Russian Academy of Sciences, Russia
}

Correspondence: Runets Oksana Vladimirovna, Laboratory of Work and Organizational Psychology, Institute of Psychology, Russian Academy of Sciences, Russia, Email orunaz@gmail.com

Received: November 24, 2017 | Published: November 27, 2018

\section{Introduction}

An interest in prosocial activity research is established since mid 19thcentury, some works that have influenced its development are those of Jean Piaget, Lawrence Kohlberg, Leonard Berkowitz, John M. Darley, Bibb Latané, Carl Rogers. Volunteer activity is a type of prosocial activity that is being intensely studied currently. Most of the researchers distinguish following characteristics of the volunteer personality: orientation on work with people and for people, overall positive world perception, altruism, responsibility, ability to cooperate with other people and to organize their activities. Generally, the specific aspects of volunteer activity are necessity to cooperate with various types of people who the helping activity is directed at and to act contextually, lack of time and resources, uncertain and extreme conditions. Successful fulfilment of a taken social responsibility relies on volunteer trust in himself, his abilities, and his partners in that activity and in people who the helping activity is directed at. A number of researchers consider trust to be a phenomenon turning interpersonal interaction in a constructive direction as self - trust and to other people facilitates personal fulfilment thus supporting cooperation on all levels of social and business communication. ${ }^{1}$ Trust to others as a psychological relationship manifests itself as an interest and respect to an object or a partner, readiness to express goodwill and to take actions encouraging successful cooperation. ${ }^{2}$ In general trust phenomenon facilitates development of harmonic relationships and suppresses asocial behavior. ${ }^{3}$ Formally, the dynamic properties of the trust manifested: the measure in the level of credibility as the basic properties; selectivity the ability to select more or less trust to another; and the partial is expressed in a variety of behavioral strategies used in the behavior acts, the more the level of credibility, the more various forms of behavior. The paper considers two formal dynamic properties of self-trust: measure and selectivity. Presented in the current work is the study of interrelation of personal prosocial activity index and levels of trust/distrust to others in groups of volunteers with various levels of self-trust. Individual psychological characteristics (altruism/ egoism, social responsibility levels) are considered as the prosocial activity indices. Based on that assumption the following hypotheses were formulated:
1. The level of self-trust is a systemic factor of volunteer prosocial activity and it determines the person orientation on altruism and social responsibility.

2. Self-trust is one of the major determinants of interpersonal interaction; it determines the structure of trust/distrust in other people.

\section{Methods}

\section{Research participants}

Current study presents the results of an internet research with 138 respondents in total. To determine the likelihood of formulated hypotheses statistical data fitting was carried out. On the basis of that fitting groups with low $(n=24)$, intermediary $(n=24)$ and high $(n=24)$ level of self-trust were detected. Respondents' age varied from 16 to 59 years, gender distribution was $81 \%$ women, $19 \%$ men.

\section{Research methods and procedure}

Level of self-trust was determined in accordance with "Method for Studying Trust to Own Self". ${ }^{3}$ Initially this method was intended to study self-trust in teenagers, later it was proved to be efficient in adult respondent research. ${ }^{4}$ Basic criteria for trust/distrust to others were defined according to "Individual trust/distrust to others estimation method". ${ }^{2}$ Study of altruism/egoism motivation was based on "Social-psychological resolution in the field of motivation and demand diagnostic method". ${ }^{5}$ Ability of a person to follow social rules and take responsibility was determined as specified in "Social responsibility scale". ${ }^{6}$ Questionnaire was offered to VK social network users who were involved in volunteer activity. Participants of that internet-based research read the instruction and filled in their forms on a special website. Statistical (correlation, dispersion and cluster) analysis of research results was carried out in STATISTICA 10 package. Additionally, for results of "Individual trust/distrust to others estimation method"7 frequency analysis was carried out.

\section{Results}

Research results have shown that in the high self-trust level group 
social responsibility index positively correlated with altruism $(\mathrm{r}=0,59$ with $p<0,01)$ meaning that these individuals are apt to act unselfishly to help others. Negative correlation between social responsibility and egoism $(\mathrm{r}=-0,51$ with $\mathrm{p}<0,01)$ characterize volunteers as people taking their responsibilities seriously. Positive correlation of altruism with "Unity with trusted one" $(\mathrm{r}=0,53$ with $\mathrm{p}<0,01)$ and "Unity $\Delta$ " $(\mathrm{r}=0,41$ with $\mathrm{p}<0,05)$ scales suggests respondents' orientation on altruistic values, ability to trust another person basing that trust on idea of common goals, principles or general mindset. That suggestion is further supported by negative correlation between altruism and "Downsides of trusted one" $(\mathrm{r}=-0,42$ with $\mathrm{p}<0,05)$ and "Downsides $\Delta$ " $(\mathrm{r}=-0,44$ with $\mathrm{p}<0,05)$. Thus, volunteers with high trust level can be characterized by tendency to act prosocial, ability to form trusting relationships based on common goals and views despite the downsides of their partners. In the intermediary self-trust level group trust/distrust to others is based on information, that suggestion is supported by positive correlation between "Self-trust" index and "Knowledge of untrusted one" scale $(r=0,56$ with $\mathrm{p}<0,01)$ and "Social responsibility" is linked with "Rationale towards trusted one" $(\mathrm{r}=0,47$ with $\mathrm{p}<0,05)$ and "Rationale $\Delta$ " $(\mathrm{r}=0,41$ with $\mathrm{p}<0,05)$. These links could be explained as following: socially responsible person trusting himself in an interaction is basing his trust on information about his partner thus mitigating the risks connected with the situation uncertainty and being able to predict behavior of a person who is not trusted in an uncertain situation. In the low self-trust level group, there is a positive correlation between altruism and social responsibility $(\mathrm{r}=0,56$ with $\mathrm{p}<0,01)$ that characterizes respondents from this group as people with respect to general social rules and ready to help others unselfishly. Trust/distrust to others however may depend on individual estimation based on mutual exchange, that assumption is supported by positive correlation between altruism and "Unity with trusted one" $(\mathrm{r}=0,44$ with $\mathrm{p}<0,05)$ and "Rationale towards trusted one" $(\mathrm{r}=0,44$ with $\mathrm{p}<0,05)$ scales, another positive correlation between social responsibility and "Unity $\Delta$ " $(\mathrm{r}=0,49$ with $\mathrm{p}<0,05)$ and "Rationale $\Delta$ " $(\mathrm{r}=0,41$ with $\mathrm{p}<0,05)$. At the same time egoism index is correlated negatively with "Downsides $\Delta$ " scale $(\mathrm{r}=-0,42$ with $\mathrm{p}<0,05)$ and positively with "Downsides of untrusted one" scale ( $\mathrm{r}=0,48$ with $\mathrm{p}<0,05)$. It is known that "Downsides $\Delta$ " index shows ambivalence of attitude to other. ${ }^{8}$ Thus on the one side volunteers with low self-trust level are oriented on their interests and on the other side they are able to realistically estimate downsides of others and be cautious about their manifestations.

To determine individual psychological characteristics and trust/ distrust to others structure in the groups with various levels of selftrust a comparative Kruskal-Wallis test was carried out. High selftrust level group has maximal orientation on altruism $(M=6 ; M=6 ; M$ $=7,5$ with $\mathrm{p}<0,05)$ and minimal orientation on egoism $(\mathrm{M}=3,5 ; \mathrm{M}=3$; $\mathrm{M}=2$ with $\mathrm{p}<0,05)$. A tendency to increase social responsibility level is recognized in high self-trust level group as compared to low selftrust level group. Additionally, some differences between these groups concerning "Reliability" criterion in trust/distrust to others structure were observed $(M=1,5 ; M=2$ with $p<0,05)$. These differences show that representatives of these two groups base their trust in interaction with others on an emotional component - reliability. Volunteers from the first group are open to interaction and they see their partner as a person who could help them in a difficult situation. Volunteers of the third group are characterized by orientation on themselves in interaction and lack of expectations concerning behavior of their partner. To prove the hypotheses of the research were used a tree like cluster analysis based on a 'distant neighbors'. Cluster analysis revealed three biggest clusters. The first one unites three qualities - basic self-trust, social responsibility and altruism. This result leads to suggestion that high self-trust level manifests as high self-attitude, person readiness to take responsibility for his actions and orientation on interaction. Second cluster contains parameters promoting formation of trust/distrust to others. It can be distinctly divided into cognitive ("Knowledge", "Unity") and emotional ("Sympathy", "Reliability") components. Unification of two clusters substantiates the results of current study and theoretical study of works by E. Erikson, J. Bowlby, T. Skripkina, A. Kupreichenko. These studies show existence of link between one's self-trust and trust to others. The third cluster includes "Orientation on egoism" and "Downsides P" indices which explain attitude of person with low self-trust level in interaction with other people. This orientation expresses as ambivalence of attitude to partners in interaction where trust to others is substituted by estimation of partner weak sides and awareness of their manifestations. Unification of this cluster with the first two supports A. Kupreichenko suggestion that "Downsides" index allows to differentiate various people and social groups and that does not contradict functionaldynamic approach that justifies self-trust division into levels.

\section{Discussion}

Qualitative analysis of trust/distrust scale values shows that with increase in respondents' self-trust role of reliability in their estimation of most trusted other gradually increases and role of downsides and rationale gradually decreases. When treating an interaction partner who did not meet trust expectations with increase in self-trust estimations based on sympathy and unity scales gradually decrease. Analysis of test scale deltas has shown that for all three groups the most important scales to base their trust on are emotional criteria - reliability and sympathy. It is worth noting that volunteers with high self-trust level are oriented on unity and knowledge criteria, that suggestion is supported by high estimations of a person who is the most trusted for them. Groups with various levels of self-trust are distinctly differentiated by levels of altruism and egoism. Data acquired in this research demonstrate that volunteers' level of selftrust is not only linked with degree of orientation on altruism or egoism and social responsibility but also with manner of expressing trust/distrust to others. In general, it is worth noting that volunteer activity is linked with prosocial activity but helping behavior may be realized out of the altruism bounds. This could be acts of help that are realized as traditional and stereotypical manifestations (cultural habits, rules of etiquette), help as a rule of mutuality (quid pro quo). Many researchers suggest that egoistical motives may also encourage volunteer activity ${ }^{8}$ and that suggestion was proven in the current research as group of volunteers with low self-trust level which is oriented on egoism in interactions is able to realistically estimate downsides of others to mitigate uncertainty risks. Results of current research demonstrate connection between volunteers' orientation on altruism and social responsibility. ${ }^{9}$ i.e. personal aptitude to conform in their behavior to social norms generally accepted in society, to fulfil their role responsibilities and readiness to be held responsible for their actions. ${ }^{6}$ According to A. Zhuravlev, social responsibility acts as one of the signs of sociopsychological maturity. ${ }^{10}$ It means that responsibility for another begins with self-trust and irresponsibility roots in person inability to self-trust and to others. ${ }^{11}$ Frequency analysis has shown that group of volunteers with high self-trust level uses bigger spectrum of criteria to trust others. According to Tabharova ${ }^{12}$ research as closure with interaction partner (prosocial activity) intensifies number of used trust criteria increases. ${ }^{12}$ That fact means that for group of volunteers 
with high self-trust level psychological distance in relationships with other people is shorter. Thus, studies have shown that self-trust level is one of the most important determinants of interpersonal interaction that defines structure of trust/distrust to others. Results obtained in current research correspond to the model of trust to others created by Levicky et al. ${ }^{13}$ That model differentiates three types of trust: trust based on rationale ("That man does what he has promised"; "I heard about his good reputation from other people"), trust based on knowledge ("I have enough experience of interacting with this person"; "I feel like I know him well"), trust based on identity ("We have common interests"; "We have common values in life"). ${ }^{13}$ It was established that for group of volunteers with high self-trust level one of the most important criteria to trust others is unity, i.e. that group is characterized by trust based on identity. In Kupreichenko typology that type is called "maximalist", he is oriented on others, for him the most important values are common goals, spiritual closure and tolerance to do insides of other people. ${ }^{2}$ In general people with higher self-trust level are oriented on others, are able to form trusted relationships based on common goal and partner reliability. Volunteers in group with intermediary self-trust level base their trust on knowledge. Representatives of that group are characterized by readiness to take responsibility for their actions and orientation on cognitive component ("Rationale" and "Knowledge") in behavior estimation of a person who did once break the trust. Volunteers with low self-trust level are characterized by manifestation of ambivalent personal qualities (altruism/egoism) in prosocial activity. They tend to substitute real trust by rationale. It is shown that this group demonstrates maximum number of interrelation between the criteria of trust/distrust to others with personal qualities. In this group increase in social responsibility leads to more frequent manifestation of aptitude to substitute trust by rationale, attach high importance to downsides of others in trust relationships. This fact proves their ambivalence in relationships with other people as they tend to preserve their ability to realistically estimate downsides and cautiously predict their possible manifestations even of their trusted interaction partners. Thus, cluster analysis results support hypothesis that self-trust is one of the major determinants of interpersonal interaction defining the structure of trust to other people and orientation on altruism, egoism and social responsibility in prosocial activity. ${ }^{14-19}$

\section{Conclusion}

1. Self-trust is a systemic factor of volunteer prosocial activity. Self-trust level determines person orientation on altruism, egoism and social responsibility.

2. Self-trust level is one of the major determinants of interpersonal interactions defining structure of trust/distrust to other people.

3. Group of volunteers with high level of self-trust are characterized by shorter psychological distance in trust relationships. For this group, the most important type of trust is the one based on identity: they rely on common goals and partner reliability criteria when forming trusting relationships.

4. For group of volunteers with intermediary level of self-trust the most important type of trust is knowledge based and taking responsibility links with rationale. Both of these qualities demonstrate orientation on cognitive component in behavior estimation of a man who broke their trust once.
5. Volunteers with low self-trust level in prosocial activity orient themselves on expectation of benefit that could show conditional trust to others. Aptitude to rationalization lessens situation uncertainty and substitute's real self-trust.

\section{Acknowledgments}

Rabota vypolnena po zadaniju FANO RF N 0159-2017-0010.

\section{Conflicts of interest}

The authors declare that there is no conflicts of interest.

\section{References}

1. Antonenko IV. Social Psychology of Duty: Diss. d.psihol $n$ Yaroslavl. 2006:498.

2. Kuprejchenko AB. Psychology of Duty and Immorality. Institute of Psychology RAN; 2008.

3. Astanina NB. Creation and approbation of a new personal questionnaire Methods for studying self-confidence. Psychological science and education. 2010;3.

4. Runets OV. Testing personal questionnaire NB Astanina Methods of studying trust in you. Social Psychology and Society. 2015;6(4):170-182.

5. Practical psycho diagnostics. Methods and tests. 2001:641-648.

6. Muzdybaev K. Psychology of responsibility. Librokom. 2010.

7. Arutjunova KR, Aleksandrov JI. Factors of gender and age in the moral assessment of actions. Psychological Journal. 2016;37(2):79-91.

8. Finkelstien MA. Intrinsic vs. extrinsic motivational orientations and the volunteer process. Personality and Individual Differences. 2009;46(56):653-658.

9. Makarenko AS. The team and the education of the individual. Pedagogy. 1972.

10. Zhuravlev AL. Socio-psychological maturity: rationale. 2007;28(2):44-55.

11. Krivosheeva OR. Practical aspects of the formation of social responsibility: a training manual. Krivosheeva - Omsk: Izd-vo SibGUFK. 2010.

12. Tabharova SP. The relationship of identity and distrust of the individual to other people with an attitude to the observance of the moral standards of business behavior. Abstract of dissertation for the degree of candidate of psychological sciences. 2008.

13. Levicky RJ, Stevenson M, Bunker BB. The three components of interpersonal trust: instrument development and differences accross relationships. The Ohio State University; 1997:25.

14. Aldasheva AA. The confidence of a professional in oneself in the space of professional activity. Social'nye and gumanitarnye learning at Dal'nem. 2016;3(51):62-71.

15. Boulbi D. Attachment. Gardariki; 2003.

16. Nakonechnaja M. Help someone else, as the disclosure of his sublectures. Journal Club Intelros Credo Nev. 2012;2.

17. Rodzhers KR. A look at psychotherapy. The formation of man. KR Rogers M: Publishing Group Progress, Univers; 1994.

18. Sergienko EA. Problems of the relationship of concepts of subject and personality. Psychol Journ. 2013;34(2):5-16.

19. Jerikson Je. Identity: youth and crisis. M Progress. 1996. 